\title{
Long non-coding RNA HOXD-AS1 promotes tumor progression and predicts poor prognosis in colorectal cancer
}

\author{
XIANG LI, XINHAN ZHAO, BINHUI YANG, YUQING LI, TAO LIU, LINYUAN PANG, \\ ZHIGANG FAN, WU MA, ZHONGQIU LIU and ZENG LI \\ Department of Second Medical Oncology, The Affiliated 3201 Hospital of Xi'an Jiaotong University, \\ Hanzhong, Shaanxi 723000, P.R. China
}

Received January 5, 2018; Accepted March 16, 2018

DOI: $10.3892 /$ ijo.2018.4400

\begin{abstract}
Mounting evidence has indicated that long non-coding RNAs (lncRNA) serve important roles in tumor development. Previous studies have demonstrated that the IncRNA HOXD cluster antisense RNA 1 (HOXD-AS1) promotes tumor progression in numerous types of cancer; however, the role of HOXD-AS1 in colorectal cancer (CRC) remains unclear. In the present study, the expression levels of HOXD-AS1 were detected in CRC tissues and cell lines using quantitative polymerase chain reaction. In addition, the biological effects of HOXD-AS1 on CRC were evaluated in vitro by cell counting kit-8, colony formation and Transwell assays, and in vivo by tumorigenesis and metastasis assays. The results demonstrated that HOXD-AS1 was upregulated in CRC tissues and cell lines, and that overexpression of HOXD-AS1 was associated with poor prognosis in patients with CRC. Furthermore, knockdown of HOXD-AS1 inhibited cell proliferation, cell invasion, epithelial-mesenchymal transition and stem cell formation in vitro, as well as tumor growth and metastasis in vivo. Mechanistically, HOXD-AS1 functioned as a competing endogenous RNA for miR-217. In conclusion, the present study demonstrated that HOXD-AS1 may promote CRC progression and metastasis by competing for miR-217. In addition, HOXD-AS1 may be considered an indicator of prognosis in patients with CRC.
\end{abstract}

\section{Introduction}

Colorectal cancer (CRC) is one of the most common types of malignancy and the third leading cause of cancer-associated

Correspondence to: Professor Zeng Li, Department of Second Medical Oncology, The Affiliated 3201 Hospital of Xi'an Jiaotong University, 783 Tianhan Road, Hanzhong, Shaanxi 723000, P.R. China E-mail: zengli0101@163.com

Abbreviations: CRC, colorectal cancer; EMT, epithelial-mesenchymal transition; lncRNA, long non-coding RNA; HOXD-AS1, HOXD cluster antisense RNA 1; siRNA, small interfering RNA

Key words: lncRNA, HOXD-AS1, CRC, tumor progression mortality worldwide (1). Great progress has been achieved with regards to CRC therapy, including targeted therapy and immune therapy; however, the prognosis of patients with advanced CRC remains poor. Tumor metastasis and progression are the main causes of cancer-associated mortality in patients with CRC (2); however, the molecular mechanisms underlying tumor metastasis and progression are complex and unclear. Therefore, it is of great importance to uncover the mechanisms underlying CRC progression and metastasis, in order to develop novel anticancer treatment options.

Sequencing of the human genome revealed that the vast majority of our genome is transcribed to produce non-coding RNAs (ncRNAs), including small and long ncRNAs (lncRNAs) (3). lncRNAs are defined as a class of non-coding RNA transcripts $>200$ nucleotides long, which have little or no protein-coding capacity (4). It has previously been reported that lncRNAs serve important roles in regulating numerous biological processes, including cell proliferation, cell invasion, cell differentiation and chromosome inactivation (5). IncRNAs can be classified into various categories, including transcripts, antisense lncRNAs, long intergenic ncRNAs and pseudogenes, according to their structure and function (6,7). They may act as scaffolds, guides, decoys and tethers of other molecules to regulate the expression of other genes (4). IncRNAs are considered novel factors in cancer research, and accumulating evidence has demonstrated that they may function as oncogenes or tumor suppressor genes, depending on the circumstance.

The HOX gene family, which was first reported in the study of homeosis in Drosophila, contains a series of evolutionarily conserved genes that have important roles in embryonic development (8). The IncRNA HOXD cluster antisense RNA 1 (HOXD-AS1), which is located between the HOXD1 and HOXD3 genes, is encoded by a member of the same gene family that encodes HOX transcript antisense RNA (HOTAIR) (9). Similar to HOTAIR, HOXD-AS1 also serves an important role in tumor progression and metastasis $(10,11)$. A recent study demonstrated that HOXD-AS1 is upregulated in bladder cancer, and affects the apoptosis and metastasis of tumor cells (12). However, the role and underlying molecular mechanisms of HOXD-AS1 in CRC development and metastasis remain to be elucidated; therefore, the present study aimed to explore the potential role and 
molecular mechanisms of HOXD-AS1 in CRC progression and metastasis.

\section{Materials and methods}

Clinical samples. The human CRC tissue and adjacent normal tissue samples used in the present study were obtained from 136 patients at the Affiliated 3201 Hospital of Xi'an Jiaotong University (Hanzhong, China). The present study was approved by the Medical Ethics Committee of the Institutional Review Board of the Affiliated 3201 Hospital of Xi'an Jiaotong University. Written informed consent was obtained from all participants in the present study. None of the patients received chemotherapy or radiotherapy prior to surgery. The clinicopathological information of the 136 patients who underwent surgery at the Affiliated 3201 Hospital of Xi'an Jiaotong University between March 2010 and May 2013, including sex, age, tumor size, tumor depth, differentiation, T stage, lymph node invasion and distant metastasis, were recorded.

Reverse transcription-quantitative polymerase chain reaction (RT-qPCR) analysis. Total RNA was extracted from tissue and cells using TRIzol ${ }^{\circledR}$ reagent (Invitrogen; Thermo Fisher Scientific, Inc., Waltham, MA, USA), according to the manufacturer's protocol. RNA was reverse transcribed into cDNA using Superscript III transcriptase, according to the manufacturer's protocol (Invitrogen; Thermo Fisher Scientific, Inc.). qPCR analysis was used to detect HOXD-AS1 expression, as previously described (13). qPCR was performed using the FastStart Universal SYBR-Green Master (\#4913914001; Roche Diagnostics, Basel, Switzerland) on an ABI QuantStudio 6 Flex system (Applied Biosystems; Thermo Fisher Scientific, Inc.) as follows: Denaturation at $95^{\circ} \mathrm{C}$ for $10 \mathrm{~min}$, followed by 40 cycles at $95^{\circ} \mathrm{C}$ for $5 \mathrm{sec}, 60^{\circ} \mathrm{C}$ for $40 \mathrm{sec}$ and $72^{\circ} \mathrm{C}$ for $45 \mathrm{sec}$. GAPDH was used as an endogenous control to normalize HOXD-AS1 expression levels. qPCR analysis of microRNA (miRNA/miR)-217 expression was performed according to a previously described method (14). qPCR analysis for the detection of Vimentin, $\mathrm{N}$-cadherin, slug, E-cadherin, $\alpha$-cadherin, $\beta$-cadherin, cluster of differentiation (CD)44, CD133, CD24, CD166, octamer-binding transcription factor 4 (Oct4), leucine-rich repeat-containing G-protein coupled receptor 5 (Lgr5), sex determining region Y-box 2 (Sox2) and Nanog was performed according to a previously described method (15). All primers for qPCR are listed in Table I. Relative quantification of RNA expression was calculated using the $2^{-\Delta \Delta \mathrm{Cq}}$ method (16). Each sample was tested in triplicate.

Cell culture. CRC cell lines [HCT116, American Type Culture Collection (ATCC)-CCL-247; SW620, ATCC-CCL-227; SW480, ATCC-CCL-228; DLD-1, ATCC-CCL-221; HT-29, ATCC-HTB-38;LoVo,ATCC-CCL-229] and the human normal colonic epithelial cell line CCD-112CoN (ATCC-CRL-1541) were purchased from the ATCC (Manassas, VA, USA). Cells were cultured according to the manufacturer's protocols: HCT116 and HT-29 cells were cultured in McCoy's 5A, SW620 and SW480 cells were cultured in Leibowitz L-15, LoVo cells were cultured in F12K, CCD-112CoN cells were cultured in DMEM, and DLD-1 cells were cultured in RPMI-1640 (all from Gibco; Thermo Fisher Scientific, Inc.). All of the media were supplemented with $10 \%$ fetal bovine serum (FBS) (Gibco; Thermo Fisher Scientific, Inc.).

Plasmid construction and cell transfection. Full-length fragments of HOXD-AS1 were obtained form HCT116 cells and subcloned into pcDNA3.1(+) vector (Thermo Fisher Scientific, Inc.) for HOXD-AS1 overexpression (forward, 5'-GGTCGA CGTTTGTGCCGCGCGC-3' and reverse, 5'-CGCGGCCGCT GACACTTTGAA-3'); the vector was subsequently named the pcDNA-HOXD-AS1 vector. SW480 cells grown to 70-80\% confluence were infected with pcDNA-HOXD-AS1 vector (150 nM) using Lipofectamine ${ }^{\circledR} 2000$ (Invitrogen; Thermo Fisher Scientific, Inc.) according to the manufacturer's protocol. In addition, HCT116 and LoVo cells were grown to 70-80\% confluence and were transfected with small interfering (si)RNA (100 nM) using Lipofectamine ${ }^{\circledR} 2000$ (Invitrogen; Thermo Fisher Scientific, Inc.) to knockdown HOXD-AS1, according to the manufacturer's protocol. siRNA targeting HOXD-AS1 and relative negative control (NC) siRNA (5'-GGCCAGAGC AGCAGGGCCC-3') were provided by Shanghai GenePharma Co., Ltd. (Shanghai, China). The target sequences used in the present study were as follow: siRNA1, 5'-GAAAGAAGGACC AAAGTAA-3'; and siRNA2, 5'-GCACAAAGGAACAAGG AAA-3'. The expression levels of HOXD-AS1 post-transfection were assessed by RT-qPCR; $48 \mathrm{~h}$ post-transfection, the cells underwent further experimentation.

Cell proliferation assays. Cell proliferation was determined using the MTT kit (Sigma-Aldrich; Merck KGaA, Darmstadt, Germany), according to the manufacturer's protocol. For the colony formation assay, CRC cells were trypsinized, and single-cell suspensions containing $3 \times 10^{3}$ cells were plated into 6-well plates and cultured with RPMI-1640 supplemented with 10\% FBS (Gibco; Thermo Fisher Scientific, Inc.). The plates were incubated at $37^{\circ} \mathrm{C}$ in an atmosphere containing $5 \% \mathrm{CO}_{2}$ for 14 days. Images of the colonies containing $\geq 50$ cells were then captured and colonies were counted by ImageJ (V.1.8.0) software [National Institutes of Health (NIH), Bethesda, MD, USA]. Data are presented as the means \pm standard deviation of five randomly scored fields.

Invasion assays. Cell invasion was assessed by Transwell assay (Corning, Inc., Corning, NY, USA), according to the manufacturer's protocol. The membrane inserts were coated with diluted Matrigel (BD Biosciences, San Jose, CA, USA). Cells $\left(1 \times 10^{5}\right)$ in $100 \mu \mathrm{l}$ serum-free medium were added to the upper chamber and cultured for $24 \mathrm{~h}$, and the lower chamber of each well insert was filled with $600 \mu 120 \%$ serum-containing medium. Subsequently, the membrane inserts were removed and stained with $0.1 \%$ crystal violet for $15 \mathrm{~min}$ at room temperature; the number of invasive cells was counted under an inverted microscope and images were captured.

Sphere-forming assays. A sphere-forming assay was performed according to a previously published method (15) with minor modifications. Briefly, cell suspensions $\left(1.0 \times 10^{3}\right.$ cells/well) were seeded in 6-well ultralow attachment plates (Corning, Inc.) in serum-free Dulbecco's modified Eagle's medium/F12 (Gibco; Thermo Fisher Scientific, Inc.) containing $20 \mathrm{ng} / \mathrm{ml}$ basic fibroblast growth factor, $20 \mathrm{ng} / \mathrm{ml}$ 
Table I. Primers used for reverse transcription-quantitative polymerase chain reaction in the present study.

Gene $\quad$ Primer sequences (5'-3')

\begin{tabular}{ll}
\hline lncRNA & F: 5'-GGCTCTTCCCTAATGTGTGG-3' \\
HOXD-AS1 & R:5'-CAGGTCCAGCATGAAACAGA-3'
\end{tabular}

N-cadherin F: 5'-GGTGGAGGAGAAGAAGACCAG-3' R:5'-GGCATCAGGCTCCACAGTG-3'

Vimentin F: 5'-GAGAACTTTGCCGTTGAAGC-3' R:5'-GCTTCCTGTAGGTGGCAATC-3'

Snail F: 5'-CCTCCCTGTCAGATGAGGAC-3' R:5'-CCAGGCTGAGGTATTCCTTG-3'

Slug F: 5'-GGGGAGAAGCCTTTTTCTTG-3' R:5'-TCCTCATGTTTGTGCAGGAG-3'

E-cadherin F: 5'-TGCCCAGAAAATGAAAAAGG-3' R:5'-GTGTATGTGGCAATGCGTTC-3'

$\alpha$-catenin $\quad$ F: 5'-AGCGAATTGTGGCAGAGTGT-3' R:5'-GTCTACGCAAGTCCCTGGTC-3'

$\beta$-catenin $\quad$ F: 5'-ACAACTGTTTTGAAAATCCA-3' R:5'-CGAGTCATTGCATACTGTCC-3'

CD44 F: 5'-TTGCAGTCAACAGTCGAAGAAG-3' R:5'-CCTTGTTCACCAAATGCACCA-3'

Oct4 F: 5'-CTTGCTGCAGAAGTGGGTGGAGGAA-3' R:5'-CTGCAGTGTGGGTTTCGGGCA-3'

CD133 F: 5'-TGGATGCAGAACTTGACAACGT-3' R:5'-ATACCTGCTACGACAGTCGTGGT-3'

CD24 F: 5'-TGAAGAACATGTGAGAGGTTTGAC-3' R:5'-GAAAACTGAATCTCCATTCCACAA-3'

CD166 F: 5'-TCCTGCCGTCTGCTCTTCT-3' R:5'-TTCTGAGGTACGTCAAGTCGG-3'

Lgr5 F: 5'-TATCTGGCTCCGAGTGCTTGCC-3' R: 5'-ATCATAGCCAGAGATGGATACC-3'

Sox2 F: 5'-GCCGATGTGAAACTTTTGTCG-3' R:5'-GGCAGCGTGACTTATCCTTCT-3

Nanog F: 5'-AATACCTCAGCCTCCAGCAGATG-3' R:5'-TGCGTCACACCATTGCTATTCTTC-3'

GAPDH F: 5'-TGCACCACCAACTGCTTAGC-3' R:5'-GGCATGGACTGTGGTCATGAG-3'

U6

F: 5'-CTCGCTTCGGCA GCACA-3' R:5'-AACGCTTCACGAATT TGCGT-3'

$\operatorname{miR}-217$
After culturing for 7 days, the size and number of tumor spheres were evaluated using light microscopy (Olympus Corporation, Tokyo, Japan).

Immunofluorescence analyses. Immunofluorescence analyses were conducted according to a previously described method (17). The following antibodies were used in the present study: E-cadherin (\#3199S) and N-cadherin (\#14215S) (both from Cell Signaling Technology, Inc., Danvers, MA, USA). A goat anti-rabbit secondary antibody immunoglobulin (Ig)G (A21537) and a goat anti-mouse $\operatorname{IgG}$ (A21538) (both from EMD Millipore, Bedford, MA, USA) were used. Sections were then visualized under a confocal laser microscope (Olympus Corporation).

RNAimmunoprecipitation(RIP)assay.RIP was performedusing a Magna RIP ${ }^{\text {тм }}$ RNA-Binding Protein Immunoprecipitation kit (EMD Millipore), according to the manufacturer's protocol. Briefly, cell lysates were incubated with RIP buffer containing magnetic beads conjugated with negative control normal mouse IgG or human anti-argonaute 2 (Ago2) antibody. The samples were then incubated with proteinase $\mathrm{K}$ to isolate immunoprecipitated RNA. Finally, the purified RNA was extracted and analyzed by qPCR to confirm the presence of the binding targets.

Lentivirus production and infection. Cells were constructed with a stable knockdown of HOXD-AS1 according to a previously published study (18). Briefly, short hairpin (sh) RNAs directed against human HOXD-AS1 (target sequence, 5'-GAAAGAAGGACCAAAGTAA-3') or scrambled oligonucleotides were ligated into the LV-3 (pGLVH1/GFP+Puro) vector (Shanghai GenePharma Co., Ltd.). Two hundreds and ninety-three cells were cotransfected with lentiviral vectors (or the control lentiviral vectors) and Lenti-Pac HIV Expression Packaging Mix using Lipofectamine ${ }^{\circledR} 2000$ (Invitrogen; Thermo Fisher Scientific, Inc.). After 48 h, lentiviral particles in the supernatant were harvested and filtered by centrifugation at $500 \mathrm{x}$ g for $10 \mathrm{~min}$. Cells were then infected with lentivirus or negative control (NC) lentivirus. To select stably transfected cells, the cells were treated with puromycin $(2 \mu \mathrm{g} / \mathrm{ml})$ for 2 weeks. Green fluorescent protein-positive cells were named sh-HOXD-AS1 and sh-NC, and were used for subsequent assays.

Tumorigenesis and metastasis assays. A total of 40 female BABL/c athymic nude mice (age, 5 weeks; weight, 15.4-17.2 g) were obtained from the Beijing Vital River Laboratory Animal Technology Co., Ltd. (Beijing, China), and were maintained in the Xi'an Jiaotong University animal facilities, approved by the China Association for Accreditation of Laboratory Animal Care. The maintenance conditions for the mice were as follows: Temperature, $26-28^{\circ} \mathrm{C}$; humidity, 40-60\%; ventilation, 10-15 times/h; 10-h light/14-h dark cycle; ad libitum access to food and water. The food and water were obtained from the Beijing Keao Cooperation Feed Co., Ltd. (Beijing, China), as recommended by the China Association for Accreditation of Laboratory Animal Care. For the tumorigenesis analysis, $1 \times 10^{6} \mathrm{sh}-\mathrm{HOXD}-\mathrm{AS} 1$ and sh-NC cells were inoculated into the right flanks of each mouse. Tumor diameter $(\mathrm{mm})$ was measured every week, and the tumor volumes were

epidermal growth factor (both from Miltenyi Biotec, Inc.) and
2 mM L-glutamine (Mediatech, Inc., Manassas, VA, USA)

$\mathrm{CD}$, cluster of differentiation; HOXD-AS1, HOXD cluster antisense RNA 1; Lgr5, leucine-rich repeat-containing G-protein coupled receptor 5; lncRNA, long non-coding RNA; miR-217, microRNA-217; Oct4, octamer-binding transcription factor 4; Sox2, sex determining region Y-box 2. F, forward; R, reverse. 
calculated using the following formula: Volume $=$ (shortest

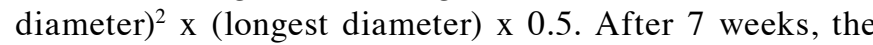
mice were sacrificed, and the tumors were excised. For the metastasis analysis, $2 \times 10^{6}$ cells were inoculated into the tail vein of each mouse. After 6 weeks, the mice were sacrificed, and the lungs and livers were excised, fixed with $4 \%$ paraformaldehyde at room temperature for $30 \mathrm{~min}$ and paraffin embedded. Consecutive tissue sections $(4 \mu \mathrm{m})$ were made and were stained with hematoxylin and eosin; micro-metastases in the lungs and livers were evaluated under a dissecting microscope. All animal experiments were performed according to the NIH guidelines on the use of experimental animals. The in vivo experiments were approved by the Ethics Committee of the Institutional Review Board of the Affiliated 3201 Hospital of Xi'an Jiaotong University on Animal Experiments.

Vector construction and luciferase reporter assay. The 3'-end fragment from HOXD-AS1 containing the predicted miR-217 binding site was extracted from HCT116 cells and amplified using PCR and subcloned into a pmirGLO Luciferase Target Expression Vector (Promega Corporation, Madison, WI, USA) to form the HOXD-AS1 wild-type (pmirGLO-HOXD-AS1-wt) vector. In addition, a mutated miR-217 binding sequence was constructed, which was subcloned into the expression vector to form the pmirGLO-HOXD-AS1-mt vector. 293T cells were cultured in a 6-well plate and grown to $70-80 \%$ confluence for cell transfection. Cell were cotransfected with pmirGLO (50 nM), pmirGLO-HOXD-AS1-wt (50 nM) or pmirGLO-HOXD-AS1-mt (50 nM), and miR-217 mimics (5'-UACUGCAUCAGGAACUGAUUGGA-3') (100 nM) or NC (5'-UUGUACUACACAAAAGUACUG-3') (100 nM) using Lipofectamine $^{\circledR} 2000$ (Invitrogen; Thermo Fisher Scientific, Inc.), and were cultured in a humidified atmosphere containing $5 \% \mathrm{CO}_{2}$ at $37^{\circ} \mathrm{C}$ for $24 \mathrm{~h}$. Finally, the relative luciferase activity was measured using the Dual-Luciferase Reporter Assay kit (Promega Corporation) after $48 \mathrm{~h}$, according to the manufacturer's protocol. For overexpression or knockdown of miR-217, HCT116 and LoVo cells grown to $70-80 \%$ confluence were transfected with miR-217 mimics $(100 \mathrm{nM})$ or NC mimics $(100 \mathrm{nM})$, and miR-217 inhibitor (5'-UACUGCAUCAGGAACUGAUUGGA-3') (100 nM) or inhibitor NC (5'-GCCUCCGGCUUCGCACCUCU-3') (100 nM) using Lipofectamine ${ }^{\circledR} 2000$ (Invitrogen; Thermo Fisher Scientific, Inc.) according to the manufacturer's protocol. The PCR primer sequences are listed in Table I.

Western blot analysis. For immunoblotting of astrocyte elevated gene-1 (AEG-1), enhancer of zeste homolog 2 (EZH2) and GAPDH, rabbit EZH2 antibody (\#5246) was purchased from Cell Signaling Technology, Inc., and rabbit AEG-1 antibody (abs124058) and mouse GAPDH antibody (ab127428) were obtained from Absin Bioscience, Inc. (Shanghai, China). Western blotting was performed as previously described (19).

Statistical analysis. All statistical analyses were performed using SPSS version 16.0 (SPSS, Inc., Chicago, IL, USA) or GraphPad 5.0 (GraphPad Software, Inc., La Jolla, CA, USA) software. Data are expressed as the means \pm standard deviation; the experiments were repeated three times. The significant differences between two groups were analyzed by Student's t-test, and between multiple groups were analyzed by one-way analysis of variance and Newman-Keuls multiple comparison test.. The association between clinicopathological parameters and HOXD-AS1 expression was analyzed using $\chi^{2}$ test as appropriate. Overall survival rate was determined using the Kaplan-Meier method with the log-rank test. Survival data were evaluated using univariate and multivariate Cox proportional hazards models. $\mathrm{P}<0.05$ was considered to indicate a statistically significant difference.

\section{Results}

HOXD-AS1 is overexpressed in CRC and is associated with poor prognosis in patients with $C R C$. The present study detected the expression levels of HOXD-AS1 in paired CRC tissues and adjacent normal tissues. As shown in Fig. 1A, HOXD-AS1 was significantly upregulated in CRC tissues compared with in adjacent normal tissues (7.656 \pm 0.755 vs. 5.888 \pm 0.472 ; $\mathrm{P}<0.001)$. Furthermore, the expression levels of HOXD-AS1 were significantly higher in tissues with distant metastasis compared with in those without distant metastasis $(9.350 \pm 0.836$ vs. $6.396 \pm 0.515$; $\mathrm{P}<0.001)$ (Fig. 1B). In addition, HOXD-AS1 expression was significantly increased in advanced stage patients compared with in earlier stage patients (Fig. 1C). To explore the prognostic implications of HOXD-AS1, patients with CRC were divided into two groups according to the median expression of HOXD-AS1 in tumor tissues (7.12); namely, a high expression group and a low expression group. The results demonstrated that patients in the high HOXD-AS1 expression group presented with significantly worse overall survival and progression-free survival compared with those in the low HOXD-AS1 expression group $(\mathrm{P}<0.01)$ (Fig. 1D and E). Notably, HOXD-AS1 expression was significantly associated with differentiation $(\mathrm{P}<0.001)$, distant metastasis $(\mathrm{P}<0.001)$ and TNM stage $(\mathrm{P}=0.009)$ (Table II). Univariate analysis demonstrated that HOXD-AS1 expression $(\mathrm{P}=0.006)$, distant metastasis $(\mathrm{P}=0.005)$ and $\mathrm{TNM}$ stage $(\mathrm{P}=0.011)$ were significantly associated with prognosis. However, multivariate analysis indicated that only HOXD-AS1 expression $(\mathrm{P}=0.018)$ was an independent prognostic factor in patients with CRC (Table III).

Knockdown of HOXD-AS1 significantly inhibits cell viability, proliferation and invasion in vitro. Since HOXD-AS1 is significantly overexpressed in CRC, the present study aimed to determine whether HOXD-AS1 is involved in the regulation of CRC cell biology. The expression levels of HOXD-AS1 were detected in CRC cell lines. The results demonstrated that HOXD-AS1 was markedly increased in CRC cell lines compared with in the normal colonic cell line CCD-112CoN $(\mathrm{P}<0.05$; Fig. 2A). Knockdown of HOXD-AS1 reduced the expression of HOXD-AS1 in HCT116 and LoVo cells by $>50 \%$, whereas overexpression of HOXD-AS1 increased the expression of HOXD-AS1 in SW480 cells by 3.2-fold $(\mathrm{P}<0.05$; Fig. 2B). The MTT assay demonstrated that knockdown of HOXD-AS1 inhibited cell viability in HCT116 cells, whereas ectopic overexpression of HOXD-AS1 promoted cell viability in SW480 cells $(\mathrm{P}<0.05$; Fig. $2 \mathrm{C}$ and $\mathrm{D})$. In addition, knockdown of HOXD-AS1 significantly inhibited colony formation in HCT116 and LoVo cells ( $\mathrm{P}<0.05$; Fig. 2E). Similarly, knockdown of HOXD-AS1 inhibited cell 

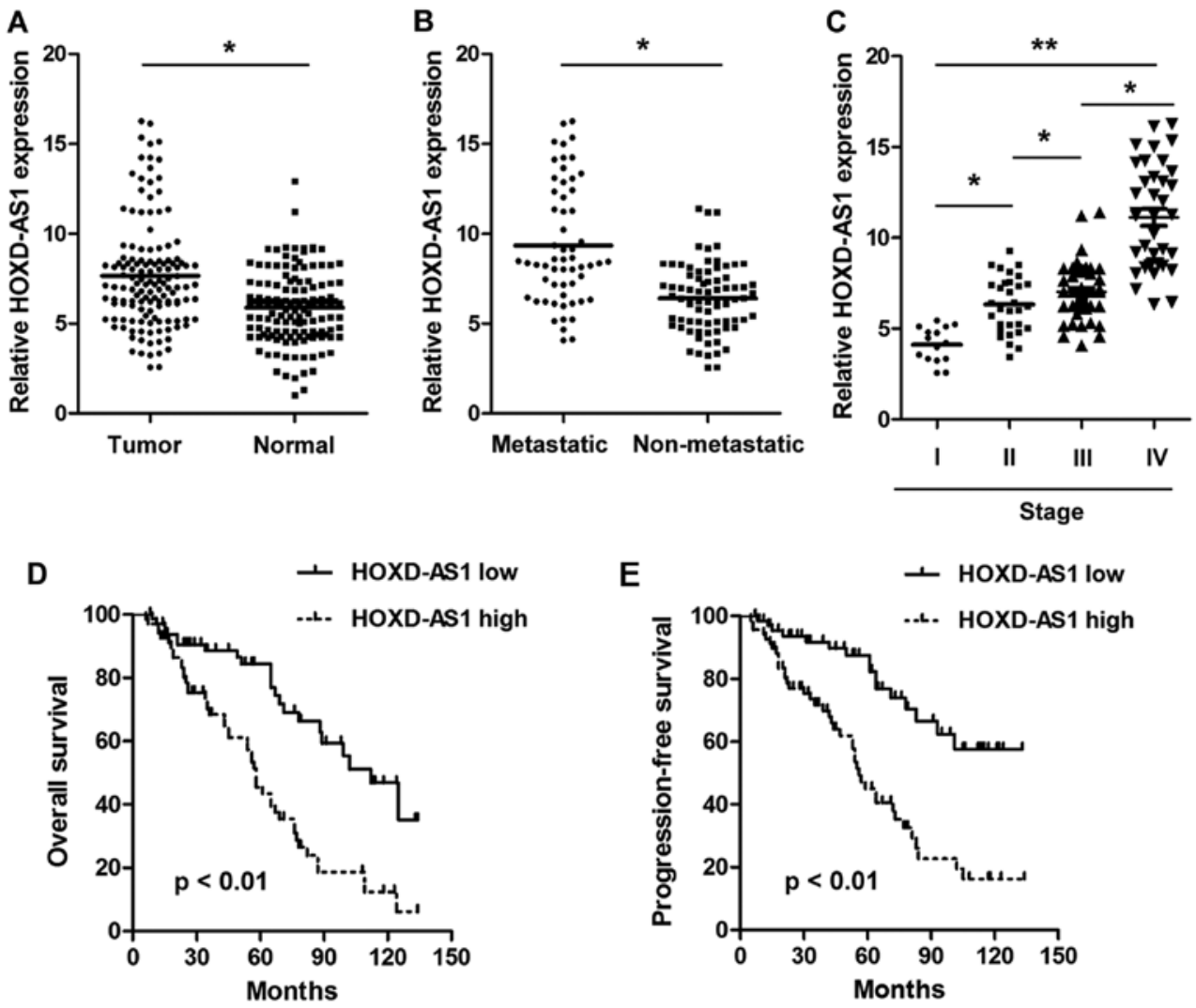

Figure 1. lncRNA HOXD-AS1 is significantly upregulated in CRC tissues. (A) RT-qPCR analysis demonstrated that lncRNA HOXD-AS1 was significantly upregulated in CRC tissues compared with in adjacent normal tissues ( $\mathrm{P}<0.001)$. (B) RT-qPCR analysis indicated that lncRNA HOXD-AS1 was significantly upregulated in CRC tissues with distant metastasis compared with in CRC tissues without metastasis ("P<0.001). (C) RT-qPCR analysis demonstrated that lncRNA HOXD-AS1 expression was higher in advanced CRC compared with in low stage CRC $\left({ }^{*} \mathrm{P}<0.05,{ }^{* * *} \mathrm{P}<0.01\right)$. (D and E) Kaplan-Meier method with log-rank test indicated that patients with high lncRNA HOXD-AS1 expression had worse overall survival and progression-free survival than those with low lncRNA HOXD-AS1 expression. CRC, colorectal cancer; HOXD-AS1, HOXD cluster antisense RNA 1; lncRNA, long non-coding RNA; RT-qPCR, reverse transcription-quantitative polymerase chain reaction.

migration and invasion in HCT116 and LoVo cells by $>50 \%$ ( $\mathrm{P}<0.05$; Fig. 2F).

Knockdown of HOXD-AS1 significantly inhibits EMT and stem cell potential in CRC cells. It has previously been reported that EMT and cancer stem cells are involved in tumor progression $(20,21)$; the present study conducted experiments to investigate this. As shown in Fig. 3A, knockdown of HOXD-AS1 increased E-cadherin expression and reduced Vimentin expression in HCT116 cells. Furthermore, RT-qPCR analysis indicated that knockdown of HOXD-AS1 decreased the expression levels of Vimentin, N-cadherin, Slug and Snail, and increased the expression levels of E-cadherin, $\alpha$-catenin and $\beta$-catenin $(\mathrm{P}<0.05$; Fig. 3B). In addition, knockdown of HOXD-AS1 inhibited stem cell formation in HCT116 and LoVo cells $(\mathrm{P}<0.05$; Fig. 3C). RT-qPCR analysis also demonstrated that knockdown of HOXD-AS1 decreased the expression levels of stem cell markers (CD44, CD133, CD24, CD166, Oct4, Lgr5, Sox2 and Nanog) in HCT116 and LoVo cells ( $\mathrm{P}<0.05$; Fig. 3D).

Knockdown of HOXD-AS1 suppresses tumorigenesis and metastasis in vivo. To explore the biological role of HOXD-AS1 in vivo, sh-HOXD-AS1 and sh-NC cells were constructed, and were implanted into mice. The results demonstrated that knockdown of HOXD-AS1 significantly inhibited tumorigenesis; the tumor weight $(0.771 \pm 0.46$ vs. $0.349 \pm 0.23 ; \mathrm{P}<0.001)$ and tumor volume $(\mathrm{P}<0.001)$ were significantly reduced in mice implanted with sh-HOXD-AS1 HCT116 cells (Fig. 4A and B). Furthermore, knockdown of HOXD-AS1 significantly suppressed liver $(9.00 \pm 1.76$ vs. $2.00 \pm 0.57 ; \mathrm{P}<0.001)$ and lung metastasis $(6.16 \pm 0.74$ vs. $2.00 \pm 0.54 ; \mathrm{P}<0.001$ ) in nude mice (Fig. $4 \mathrm{C}$ and $\mathrm{D}$ ).

HOXD-AS1 acts as a sponge of miR-217 in CRC cells. It has previously been reported that some lncRNAs can act as competing endogenous (ce)RNAs for miRNAs. In the present study, using bioinformatics tools (miRcode, http://www. mircode.org/), it was identified that HOXD-AS1 contains some miRNA-binding sites. However, further analysis indicated that only miR-217 could regulate the expression of HOXD-AS1 in CRC cells (data not shown); therefore, the present study focused on miR-217 (Figs. 5 and 6). miR-217-binding sites were detected in HOXD-AS1 at chr2-q31.1 (Fig. 5A). Subsequently, miR-217 was overexpressed or knocked down in HCT116 and LoVo cells following transfection with miR-217 mimics or a miR-217 inhibitor; successful transfection was confirmed by RT-qPCR (Fig. 6). In addition, HOXD-AS1 expression was significantly inhibited in HCT116 and LoVo cells transfected with miR-217 mimics (P<0.05; Fig. 5B); however, knockdown of HOXD-AS1 did not affect the expression levels of miR-217 (Fig. 5C). Inhibition of miR-217 led to increased expression of HOXD-AS1; however, increased expression of HOXD-AS1 caused by miR-217 
A

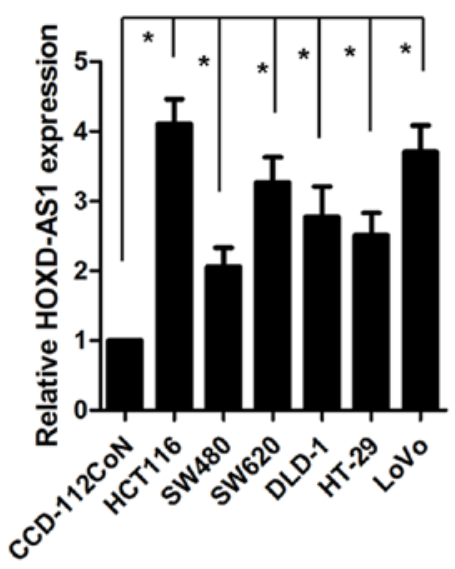

D

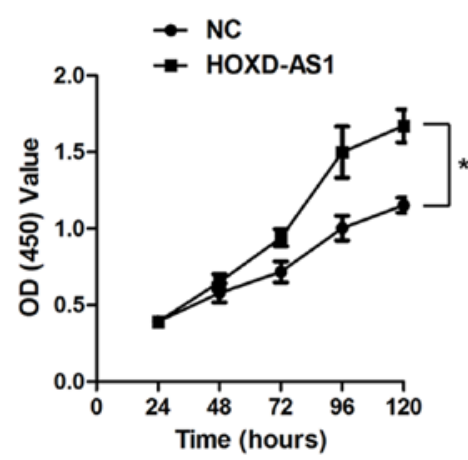

F

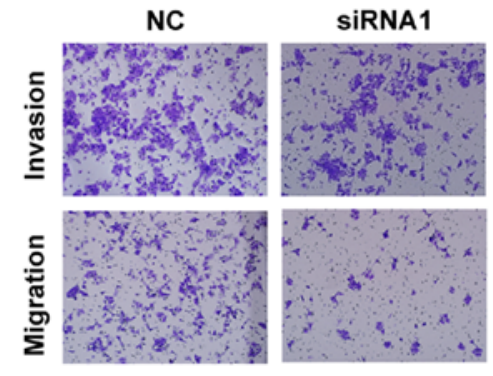

HCT116
B

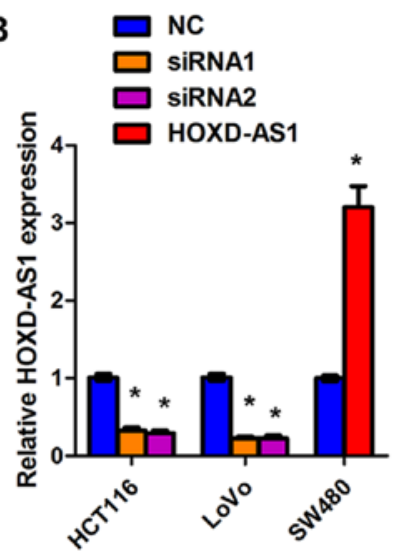

E

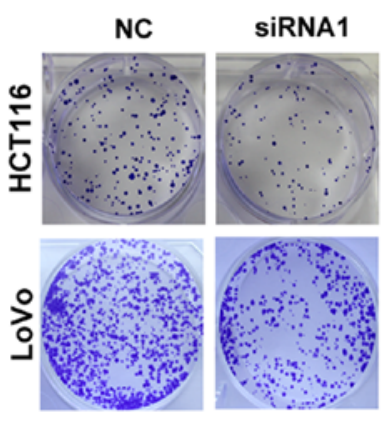

C
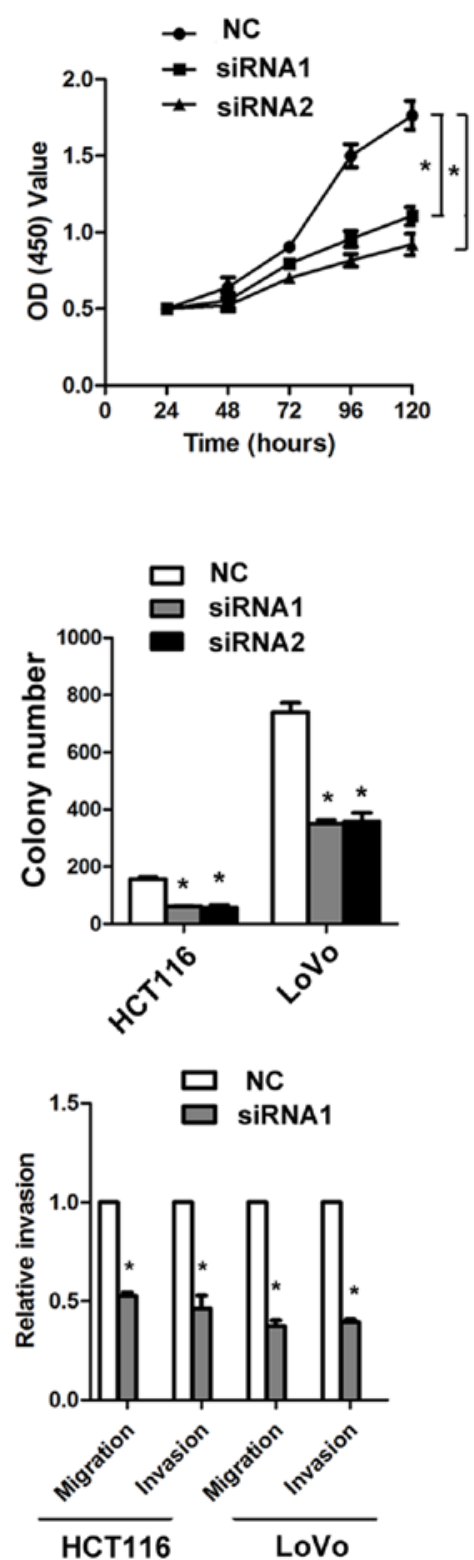

Figure 2. IncRNA HOXD-AS1 regulates CRC proliferation and invasion in vitro. (A) Relative expression levels of lncRNA HOXD-AS1 in CRC cell lines and the normal colonic epithelial cell line CCD-112CoN ( $\mathrm{P}<0.05)$. (B) Reverse transcription-quantitative polymerase chain reaction analysis demonstrated that knockdown of lncRNA HOXD-AS1 decreased the expression of 1ncRNA HOXD-AS1 in HCT116 and LoVo cells, whereas ectopic overexpression of lncRNA HOXD-AS1 increased the expression of lncRNA HOXD-AS1 in SW480 cells ("P<0.05 vs. NC). (C and D) MTT assay indicated that knockdown of HOXD-AS1 inhibited cell proliferation in HCT116 cells, whereas ectopic overexpression of HOXD-AS1 promoted cell proliferation in SW480 cells ("P<0.05). (E) Knockdown of HOXD-AS1 inhibited colony formation in HCT116 and LoVo cells ("P<0.05 vs. NC). (F) Knockdown of HOXD-AS1 inhibited cell migration and invasion of HCT116 and LoVo cells ("P<0.05 vs. NC). Magnification, x100. CRC, colorectal cancer; HOXD-AS1, HOXD cluster antisense RNA 1; lncRNA, long non-coding RNA; NC, negative control; OD, optical density; siRNA, small interfering RNA.

inhibition could be reduced by the suppression of HOXD-AS1 $(\mathrm{P}<0.05$; Fig. 5D). Furthermore, overexpression of miR-217 significantly reduced luciferase activity in cells transfected with pmirGLO-HOXD-AS1-wt, but not in cells transfected with pmirGLO-HOXD-AS1-mt (Fig. 5E). In addition, RIP analysis indicated that miR-217 and HOXD-AS1 could be significantly enriched in HCT116 and LoVo cells, as Ago2 is the vital component of the RNA-induced silencing complex (RISC), thus indicating that miR-217 and HOXD-AS1 are in the same RISC ( $<<0.05$; Fig. 5F and G). Furthermore, the present study performed western blotting, the results of which confirmed that knockdown of HOXD-AS1 decreased the protein expression levels of AEG-1 and EZH2 in CRC cells (Fig. 7).

\section{Discussion}

Numerous studies have indicated that lncRNAs are frequently dysregulated in tumors, including CRC $(22,23)$. Some lncRNAs are considered biomarkers for the diagnosis, prognosis and treatment of various tumors. For example, it has been reported that colorectal cancer-associated lncRNA promotes CRC progression through activating the $\mathrm{Wnt} / \beta$-catenin signaling 
A

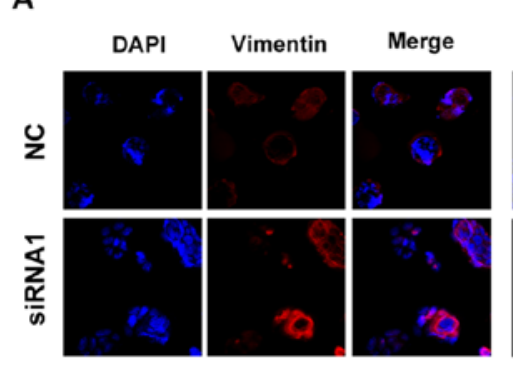

C

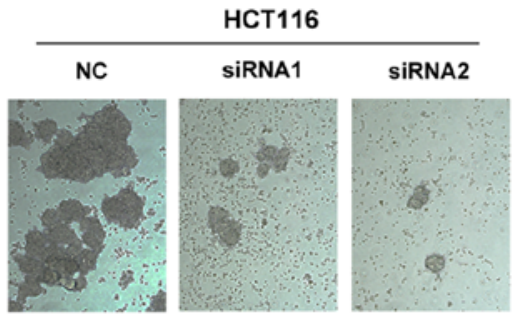

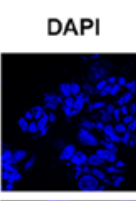

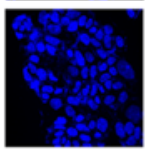

B

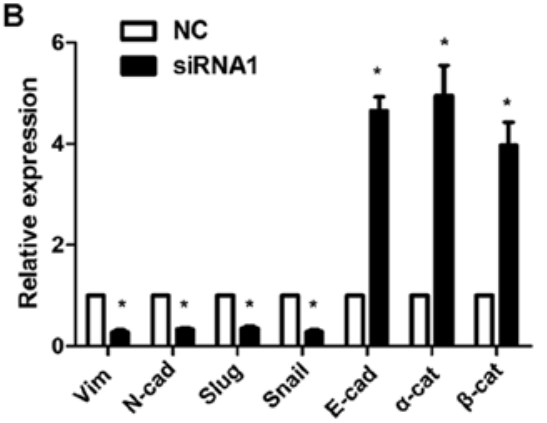

D
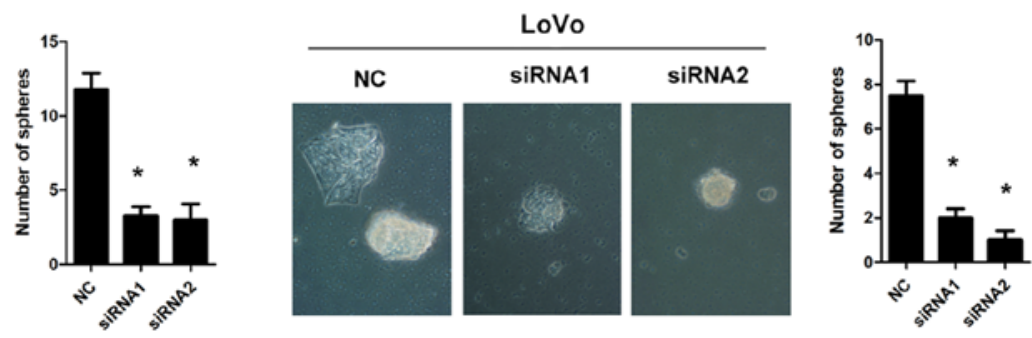

HCT116

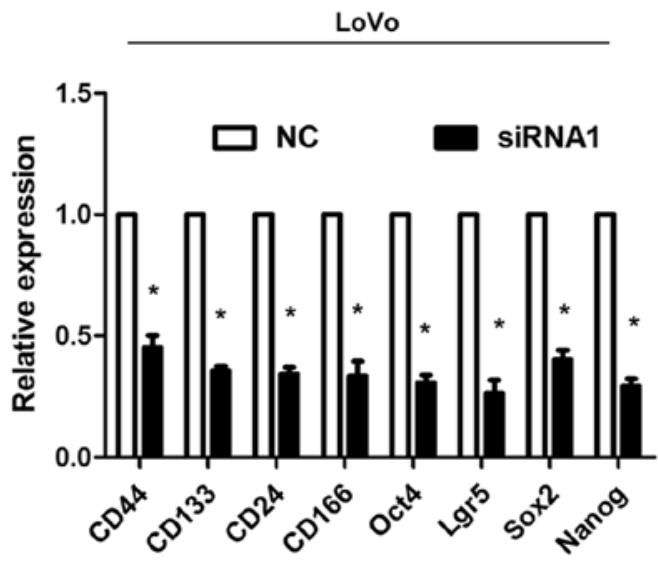

Figure 3. Long non-coding RNA HOXD-AS1 regulates epithelial-mesenchymal transition and stem cell formation in colorectal cancer cells. (A) Knockdown of HOXD-AS1 increased E-cadherin expression and reduced Vimentin expression in HCT116 cell. Magnification, x200. (B) RT-qPCR analysis demonstrated that knockdown of HOXD-AS1 decreased the expression levels of Vimentin, $\mathrm{N}$-cadherin, Slug and Snail, and increased the expression of E-cadherin, $\alpha$-catenin and $\beta$-catenin in HCT116 cells ("P $<0.05$ vs. NC). (C) Knockdown of HOXD-AS1 inhibited stem cell formation in HCT116 and LoVo cells ("P $<0.05$ vs. NC). Magnification, x200. (D) RT-qPCR analysis demonstrated that knockdown of HOXD-AS1 decreased the expression levels of stem cell markers (CD44, CD133, CD24, CD166, Oct4, Lgr5, Sox2 and Nanog) in HCT116 and LoVo cells ("P<0.05 vs. NC). CD, cluster of differentiation; HOXD-AS1, HOXD cluster antisense RNA 1; Lgr5, leucine-rich repeat-containing G-protein coupled receptor 5; NC, negative control; Oct4, octamer-binding transcription factor 4; siRNA, small interfering RNA; Sox2, sex determining region Y-box 2.

pathway via inhibition of activator protein $2 \alpha(24)$. In addition, Chen et al revealed that the lncRNA X-inactive specific transcript (XIST) promotes CRC progression and metastasis by regulating EMT (25). The present study demonstrated that the lncRNA HOXD-AS1 was significantly upregulated in CRC tissues and cell lines. Overexpression of HOXD-AS1 was associated with an aggressive tumor phenotype and poor prognosis in CRC. Furthermore, HOXD-AS1 was identified as an independent prognostic indicator in patients with CRC. These results demonstrated that HOXD-AS1 may be an important biomarker in CRC.

The results of present in vitro and in vivo experiments indicated that HOXD-AS1 may regulate cell proliferation, cell migration and cell invasion, thus resulting in increased tumorigenesis and metastasis in CRC. In agreement with the present results, previous studies have reported that HOXD-AS1 is involved in the progression and metastasis of bladder cancer, gastric cancer and hepatocellular carcinoma $(12,13,26)$. These results highlighted the potential of targeting HOXD-AS1 as a novel therapeutic strategy in CRC.

EMT is an important process associated with tumor metastasis and cancer stem cells are the major source of tumor progression; therefore, the present study investigated the effects of HOXD-AS1 on EMT and stem cells in CRC. The results demonstrated that knockdown of HOXD-AS1 inhibited EMT and stem cell properties in CRC. This finding is in agreement with previous reports that demonstrated that cancer stem cells are the key source of tumor progression and metastasis (20). Notably, a direct relationship has been observed between EMT and enhanced stem cell properties (21). Taken together, these data suggested that HOXD-AS1 may promote EMT and stem cell properties, thus resulting in enhanced proliferation, migration and invasion, finally accelerating tumor progression and metastasis. 

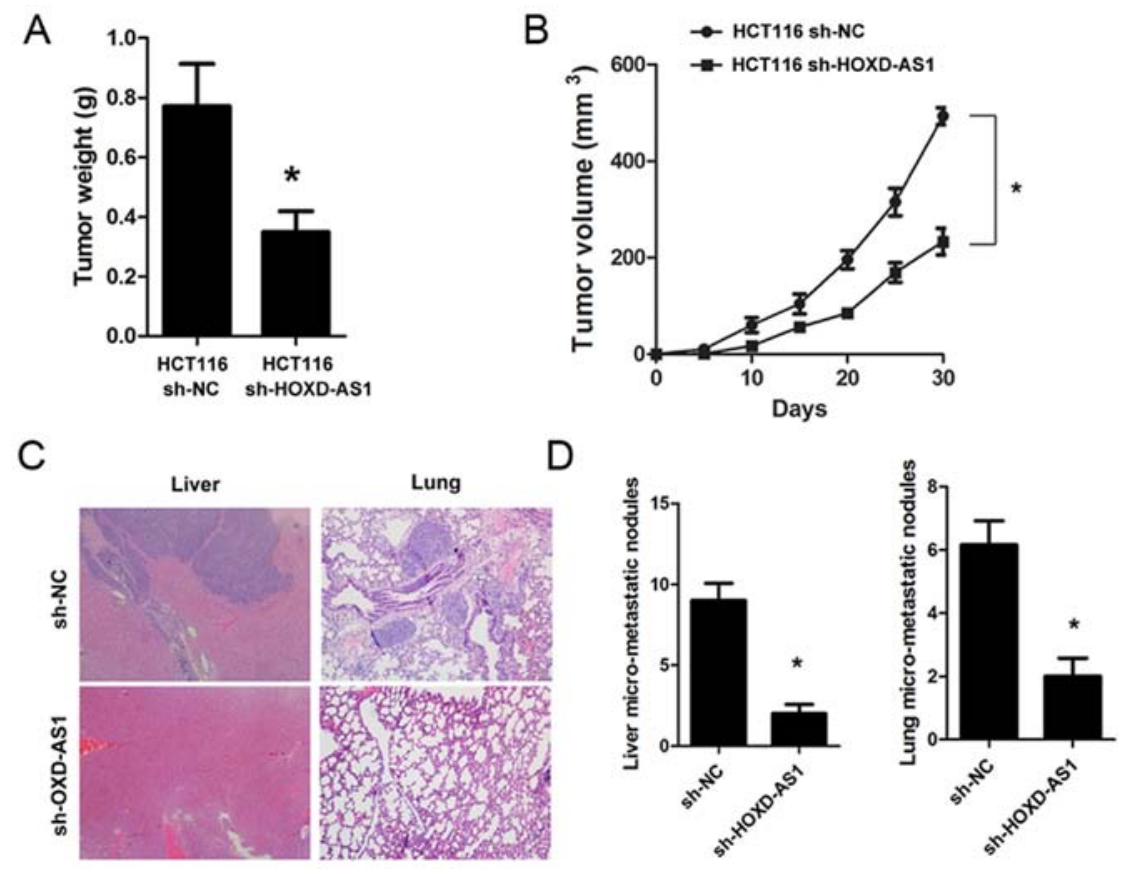

Figure 4. Knockdown of HOXD-AS1 inhibits tumorigenesis and metastasis in vivo. (A and B) Knockdown of HOXD-AS1 significantly inhibited tumorigenesis; tumor weight and volume were significantly reduced upon knockdown of HOXD-AS1 ("P<0.001). (C and D) Knockdown of HOXD-AS1 significantly suppressed liver and lung metastasis in nude mice ("P<0.001). Magnification, x200. HOXD-AS1, HOXD cluster antisense RNA 1; NC, negative control; sh, short hairpin RNA

Table II. Association between clinicopathological parameters and long non-coding RNA HOXD cluster antisense RNA 1 expression in 136 patients with colorectal cancer.

\begin{tabular}{|c|c|c|c|c|}
\hline Characteristic & $\mathrm{n}$ & $\begin{array}{c}\text { High } \\
\text { expression }\end{array}$ & $\begin{array}{c}\text { Low } \\
\text { expression }\end{array}$ & $\mathrm{P}$-value \\
\hline Age (years) & & & & 0.492 \\
\hline$<60$ & 64 & 30 & 34 & \\
\hline$\geq 60$ & 72 & 38 & 34 & \\
\hline Sex & & & & 0.729 \\
\hline Male & 78 & 38 & 40 & \\
\hline Female & 58 & 30 & 28 & \\
\hline Tumor size & & & & 0.122 \\
\hline$<4 \mathrm{~cm}$ & 71 & 31 & 40 & \\
\hline$\geq 4 \mathrm{~cm}$ & 65 & 37 & 28 & \\
\hline Differentiation & & & & $<0.001$ \\
\hline Well & 28 & 9 & 19 & \\
\hline Moderate & 63 & 24 & 39 & \\
\hline Poor & 45 & 35 & 10 & \\
\hline Lymph node invasion & & & & 0.855 \\
\hline Absent & 45 & 22 & 23 & \\
\hline Present & 91 & 46 & 45 & \\
\hline Distant metastasis & & & & $<0.001$ \\
\hline Absent & 84 & 31 & 53 & \\
\hline Present & 52 & 37 & 15 & \\
\hline TNM stage & & & & 0.009 \\
\hline I-II & 42 & 14 & 28 & \\
\hline III-IV & 94 & 54 & 40 & \\
\hline
\end{tabular}

Data were analyzed using the $\chi^{2}$ test.
An increasing number of studies have indicated that a widespread interaction network exists involving ceRNAs, in which lncRNAs can sequester miRNAs, titrating them off their binding sites on mRNAs (27). For example, lncRNA highly upregulated in liver cancer is overexpressed in liver carcinoma and can promote tumor progression via the suppression of miR-372 (28). In addition, it has been reported that the lncRNA H19 acts as a ceRNA to regulate let-7 expression, thus promoting breast cancer progression (29). Recently, Chen et al reported that the lncRNA XIST may promote gastric cancer by acting as a ceRNA for miR-101 to regulate EZH2 expression (18). The present study used a bioinformatics database and identified several miRNAs that may interact with HOXD-AS1. Notably, miR-217 was confirmed to be regulated by HOXD-AS1 in CRC cells according to the following evidence: i) Ectopic overexpression of miR-217 could decrease the expression of HOXD-AS1, whereas inhibition of miR-217 increased the expression of HOXD-AS1; ii) luciferase activity assay confirmed that miR-217 could bind to the 3'-untranslated region of HOXD-AS1; iii) RIP analysis indicated that miR-217 and HOXD-AS1 could be significantly enriched in HCT116 and LoVo cells by Ago2. A previous study demonstrated that IncRNAs can regulate the expression of miRNAs (18); however, the present study indicated that HOXD-AS1 did not affect the expression of miR-217; the underlying mechanisms require further exploration. Similar to these results, it has been reported that HOXD-AS1 acts as a ceRNA for miR-19a in hepatocellular carcinoma (13). Previous studies indicated that miR-217 may inhibit cell proliferation and induce cell apoptosis in CRC cells (30,31). Notably, it has been revealed that miR-217 may suppress EMT in other malignancies, such as gastric cancer (32), lung cancer (33) and pancreatic cancer (34). The present study confirmed that HOXD-AS1 could act as a ceRNA for miR-217; this finding may partly explain why 
A

chr2-p chr2-q31.1 chr2-q

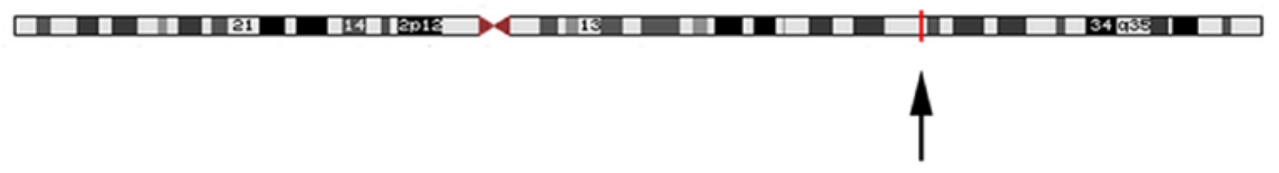

miR217 binding sites

B

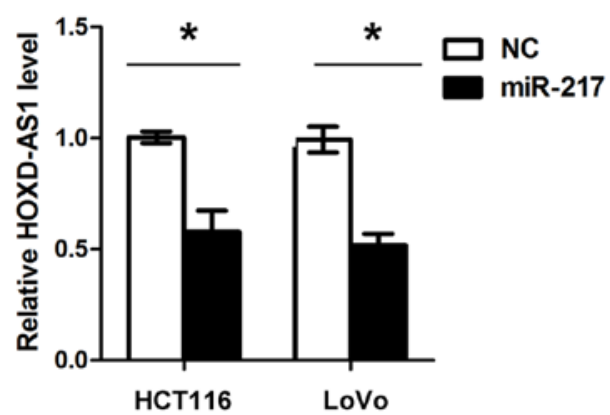

D

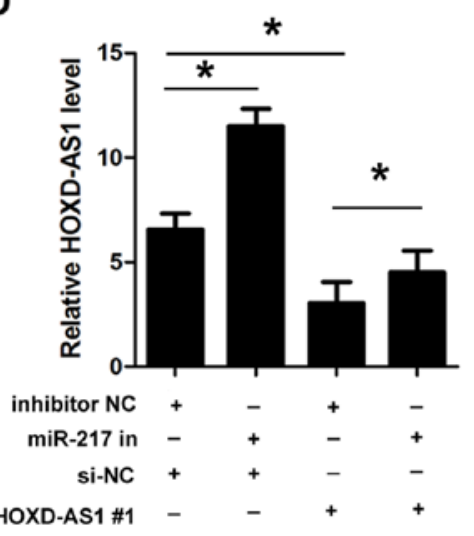

F

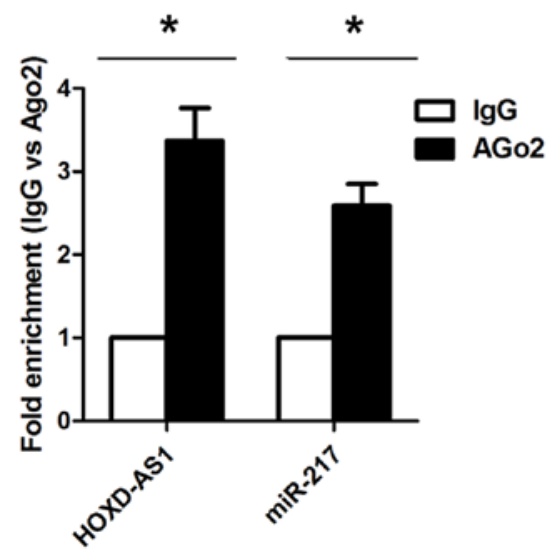

C

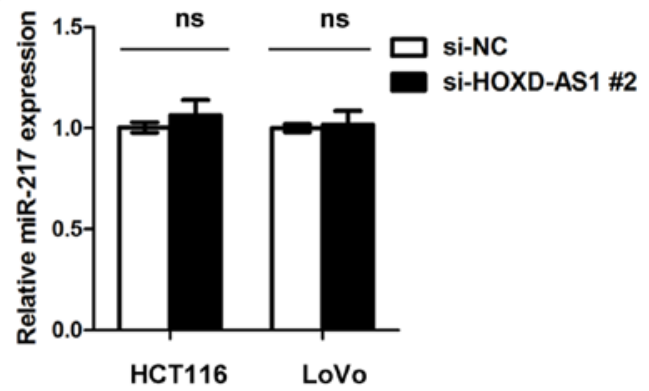

E

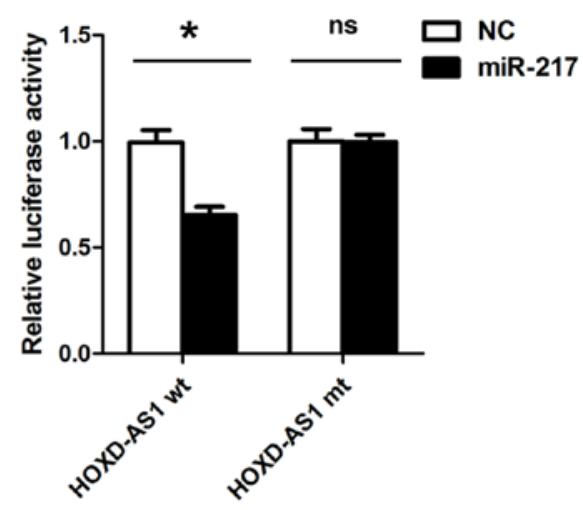

G

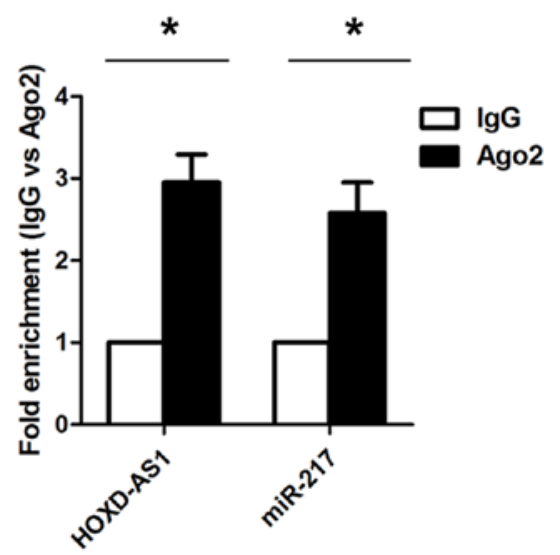

Figure 5. HOXD-AS1 acts as a sponge of miR-217 in CRC cells. (A) Binding sites between HOXD-AS1 and miR-217 at chr2-q31.1. (B) Overexpression of miR217 significantly inhibited the expression of HOXD-AS1 in HCT116 and LoVo cells ("P<0.05). (C) Knockdown of HOXD-AS1 did not affect the expression levels of miR-217. (D) Inhibition of miR-217 led to increased expression of HOXD-AS1; however, the increased expression of HOXD-AS1 caused by miR-217 inhibition could be reduced by suppression of HOXD-AS1 ("P $<0.05)$. (E) Ectopic overexpression of miR-217 significantly reduced the luciferase activity in cells transfected with the HOXD-AS1 wt vector, but not in those transfected with the HOXD-AS1 mt vector ("P<0.05). RNA immunoprecipitation analysis indicated that miR-217 and HOXD-AS1 could be significantly enriched in (F) HCT116 cells and (G) LoVo cells ("P<0.05). Ago2, argonaute 2; HOXD-AS1, HOXD cluster antisense RNA 1; IgG, immunoglobulin G; miR-217, microRNA-217; mt, mutant; NC, negative control; ns, not significant; si, small interfering; wt, wild-type.

HOXD-AS1 regulates proliferation and EMT in CRC cells. To investigate whether HOXD-AS1 regulates the target genes of miR-217, western blotting was conducted and the results confirmed that knockdown of HOXD-AS1 was able to decrease the expression of AEG-1 and EZH2 in CRC cells. AEG-1 and EZH2 have been reported to be target genes of miR-217 in previous studies $(30,35,36)$. These findings further confirmed that HOXD-AS1 may function as a ceRNA for miR-217. 
Table III. Univariate and multivariate analysis of potential prognostic factors in 136 patients with colorectal cancer.

\begin{tabular}{|c|c|c|c|c|}
\hline \multirow[b]{2}{*}{ Characteristic } & \multicolumn{2}{|c|}{ Univariate analysis } & \multicolumn{2}{|c|}{ Multivariate analysis } \\
\hline & $\mathrm{HR}(95 \% \mathrm{CI})$ & P-value & $\mathrm{HR}(95 \% \mathrm{CI})$ & P-value \\
\hline Age (years) & $0.85(0.65-1.23)$ & 0.157 & - & - \\
\hline Sex & $1.13(0.73-1.51)$ & 0.541 & - & - \\
\hline Differentiation & $1.09(0.88-1.49)$ & 0.159 & - & - \\
\hline Tumor size & $1.07(0.82-1.34)$ & 0.657 & - & - \\
\hline Lymph node invasion & $1.23(1.13-1.90)$ & 0.134 & - & - \\
\hline Distant metastasis & $1.45(1.04-2.13)$ & $0.005^{\mathrm{a}}$ & $1.12(1.04-1.99)$ & 0.103 \\
\hline TNM stage & $1.16(1.07-2.15)$ & $0.011^{\mathrm{a}}$ & $1.18(1.03-1.72)$ & 0.151 \\
\hline HOXD-AS1 level & $1.67(1.55-2.61)$ & $0.006^{\mathrm{a}}$ & $1.51(1.21-2.53)$ & $0.018^{\mathrm{a}}$ \\
\hline
\end{tabular}

${ }^{\mathrm{a}} \mathrm{P}<0.05$. CI, confidence interval; HOXD-AS1, HOXD cluster antisense RNA 1; HR, hazard ratio.
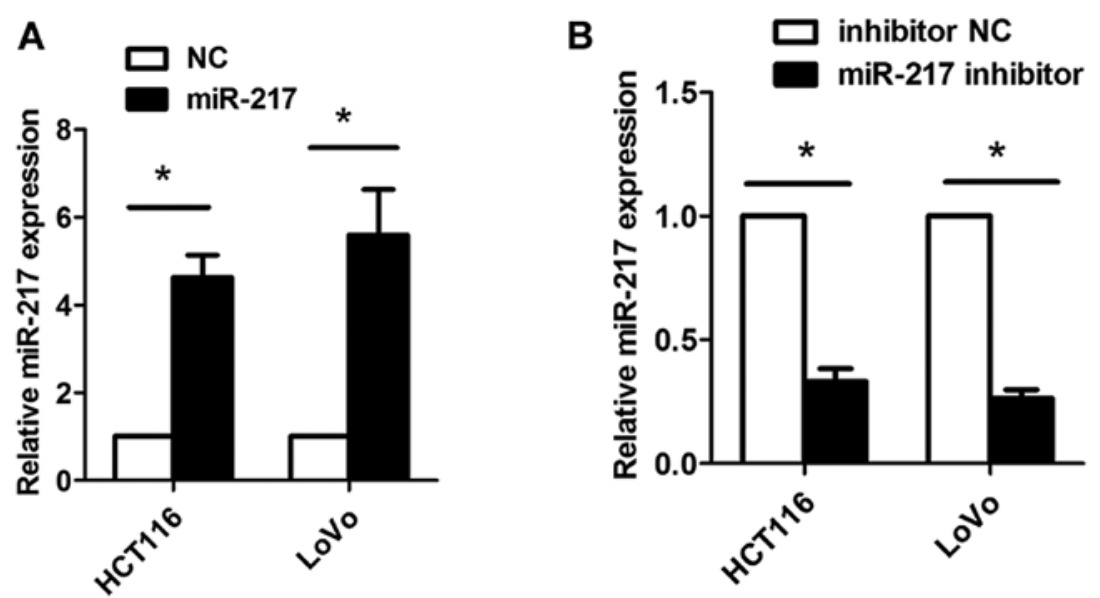

Figure 6. (A) Ectopic overexpression of miR-217 increased the expression of miR-217 in HCT116 and LoVo cells ("P<0.05). (B) Knockdown of miR-217 with a miR-217 inhibitor decreased the expression of miR-217 in HCT116 and LoVo cells ( $\mathrm{P}<0.05)$. miR-217, microRNA-217; NC, negative control.

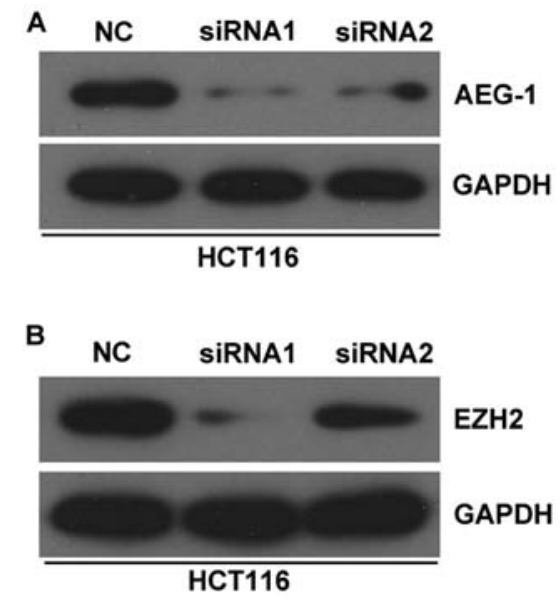

Figure 7. HOXD-AS1 regulates the expression of AEG-1 and EZH2. Western blotting indicated that knockdown of HOXD-AS1 decreased the protein expression levels of (A) AEG-1 and (B) EZH2 in HCT116 cells. AEG-1, astrocyte elevated gene-1; EZH2, enhancer of zeste homolog 2; NC, negative control; siRNA, small interfering RNA.

In conclusion, to the best of our knowledge, the present study is the first to indicate that HOXD-AS1 is significantly upregulated in CRC tissues and cell lines. HOXD-AS1 expression was also significantly associated with aggressive tumor phenotype and poor prognosis in patients with CRC. Knockdown of HOXD-AS1 inhibited CRC cell proliferation, migration, EMT and stem cell formation in vitro, as well as tumor growth and metastasis in vivo. Therefore, HOXD-AS1 may be considered a useful tumor biomarker in CRC, and targeting HOXD-AS1 may be a novel therapeutic strategy for patients with CRC.

\section{Acknowledgements}

Not applicable.

\section{Funding}

The present study was supported by the National Natural Science Foundation of China (grant no. 81372533).

\section{Availability of data and materials}

All data generated or analyzed during this study are included in this published article. 


\section{Authors' contributions}

XL, YL, and LP performed the molecular studies and drafted the manuscript. $\mathrm{XZ}$ and $\mathrm{ZF}$ performed the in vivo assays. BY and TL collected the clinical data and tissue samples. WM and $\mathrm{ZhL}$ performed the statistical analysis. ZeL designed the study and helped to draft the manuscript. All authors read and approved the final manuscript.

\section{Ethics approval and consent to participate}

The present study was approved by the Ethics Committee of the Affiliated 3201 Hospital of Xi'an Jiaotong University (Hanzhong, China), and written informed consent was obtained from all patients. All of the animal experiments were performed according to the National Institutes of Health (Bethesda, MD, USA) guidelines on the use of experimental animals, and were approved by the Ethics Committee of the Institutional Review Board of the Affiliated 3201 Hospital of Xi'an Jiaotong University on Animal Experiments.

\section{Consent for publication}

Consent for the publication of the clinical and pathological data was obtained from all patients who were involved in this study.

\section{Competing interests}

The authors declare that they have no competing interests.

\section{References}

1. Torre LA, Bray F, Siegel RL, Ferlay J, Lortet-Tieulent J and Jemal A: Global cancer statistics, 2012. CA Cancer J Clin 65 87-108, 2015.

2. Goldstein DA, Zeichner SB, Bartnik CM, Neustadter E and Flowers CR: Metastatic Colorectal Cancer: A Systematic Review of the Value of Current Therapies. Clin Colorectal Cancer 15: 1-6, 2016.

3. Esteller M: Non-coding RNAs in human disease. Nat Rev Genet 12: 861-874, 2011.

4. Wang KC and Chang HY: Molecular mechanisms of long noncoding RNAs. Mol Cell 43: 904-914, 2011.

5. Rinn JL and Chang HY: Genome regulation by long noncoding RNAs. Annu Rev Biochem 81: 145-166, 2012.

6. Tsai MC, Manor O, Wan Y, Mosammaparast N, Wang JK, Lan F, Shi Y, Segal E and Chang HY: Long noncoding RNA as modular scaffold of histone modification complexes. Science 329: 689-693, 2010

7. Wang KC, Yang YW, Liu B, Sanyal A, Corces-Zimmerman R, Chen Y, Lajoie BR, Protacio A, Flynn RA, Gupta RA, et al: A long noncoding RNA maintains active chromatin to coordinate homeotic gene expression. Nature 472: 120-124, 2011.

8. Graham A, Papalopulu N and Krumlauf R: The murine and Drosophila homeobox gene complexes have common features of organization and expression. Cell 57: 367-378, 1989.

9. Rinn JL, Kertesz M, Wang JK, Squazzo SL, Xu X, Brugmann SA, Goodnough LH, Helms JA, Farnham PJ, Segal E, et al: Functional demarcation of active and silent chromatin domains in human HOX loci by noncoding RNAs. Cell 129: 1311-1323, 2007.

10. Wang H, Huo X, Yang XR, He J, Cheng L, Wang N, Deng X, Jin $\mathrm{H}$, Wang $\mathrm{N}$, Wang $\mathrm{C}$, et al: STAT3-mediated upregulation of IncRNA HOXD-AS1 as a ceRNA facilitates liver cancer metastasis by regulating SOX4. Mol Cancer 16: 136, 2017.

11. Gu P, Chen X, Xie R, Han J, Xie W, Wang B, Dong W, Chen C, Yang M, Jiang J, et al: lncRNA HOXD-AS1 regulates proliferation and chemo-resistance of castration-resistant prostate cancer via recruiting WDR5. Mol Ther 25: 1959-1973, 2017.
12. Li J, Zhuang C, Liu Y, Chen M, Chen Y, Chen Z, He A, Lin J, Zhan Y, Liu L, et al: Synthetic tetracycline-controllable shRNA targeting long non-coding RNA HOXD-AS1 inhibits the progression of bladder cancer. J Exp Clin Cancer Res 35: 99, 2016.

13. Lu S, Zhou J, Sun Y, Li N, Miao M, Jiao B and Chen H: The noncoding RNA HOXD-AS1 is a critical regulator of the metastasis and apoptosis phenotype in human hepatocellular carcinoma. Mol Cancer 16: 125, 2017.

14. Zhao WG, Yu SN, Lu ZH, Ma YH, Gu YM and Chen J: The miR-217 microRNA functions as a potential tumor suppressor in pancreatic ductal adenocarcinoma by targeting KRAS. Carcinogenesis 31: 1726-1733, 2010.

15. Zhang JX, Chen ZH, Xu Y, Chen JW, Weng HW, Yun M, Zheng ZS, Chen C, Wu BL, Li EM, et al: Downregulation of MicroRNA-644a promotes esophageal squamous cell carcinoma aggressiveness and stem cell-like phenotype via dysregulation of PITX2. Clin Cancer Res 23: 298-310, 2017.

16. Livak KJ and Schmittgen TD: Analysis of relative gene expression data using real-time quantitative PCR and the 2(-Delta Delta C(T)) method. Methods 25: 402-408, 2001.

17. Lu YX, Ju HQ, Wang F, Chen LZ, Wu QN, Sheng H, Mo HY, Pan ZZ, Xie D, Kang TB, et al: Inhibition of the NF- $\mathrm{kB}$ pathway by nafamostat mesilate suppresses colorectal cancer growth and metastasis. Cancer Lett 380: 87-97, 2016.

18. Chen DL, Ju HQ, Lu YX, Chen LZ, Zeng ZL, Zhang DS, Luo HY, Wang F, Qiu MZ, Wang DS, et al: Long non-coding RNA XIST regulates gastric cancer progression by acting as a molecular sponge of miR-101 to modulate EZH2 expression. J Exp Clin Cancer Res 35: 142, 2016.

19. Teng KY, Qiu MZ, Li ZH, Luo HY, Zeng ZL, Luo RZ, Zhang HZ, Wang ZQ, Li YH and Xu RH: DNA polymerase $\eta$ protein expression predicts treatment response and survival of metastatic gastric adenocarcinoma patients treated with oxaliplatin-based chemotherapy. J Transl Med 8: 126, 2010.

20. Thiery JP, Acloque H, Huang RY and Nieto MA: Epithelialmesenchymal transitions in development and disease. Cell 139: 871-890, 2009.

21. Chen T, You Y, Jiang H and Wang ZZ: Epithelial-mesenchymal transition (EMT): A biological process in the development, stem cell differentiation, and tumorigenesis. J Cell Physiol 232: 3261-3272, 2017.

22. Jiang $\mathrm{C}$, Li X, Zhao $\mathrm{H}$ and Liu H: Long non-coding RNAs: Potential new biomarkers for predicting tumor invasion and metastasis. Mol Cancer 15: 62, 2016.

23. Ulitsky I and Bartel DP: lincRNAs: Genomics, evolution, and mechanisms. Cell 154: 26-46, 2013.

24. Ma Y, Yang Y, Wang F, Moyer MP, Wei Q, Zhang P, Yang Z, Liu W, Zhang $\mathrm{H}$, Chen $\mathrm{N}$, et al: Long non-coding RNA CCAL regulates colorectal cancer progression by activating $\mathrm{Wnt} / \beta$-catenin signalling pathway via suppression of activator protein $2 \alpha$. Gut 65 : 1494-1504, 2016.

25. Chen DL, Chen LZ, Lu YX, Zhang DS, Zeng ZL, Pan ZZ, Huang P, Wang FH, Li YH, Ju HQ, et al: Long noncoding RNA XIST expedites metastasis and modulates epithelialmesenchymal transition in colorectal cancer. Cell Death Dis 8: e3011, 2017.

26. Zheng L, Chen J, Zhou Z and He Z: Knockdown of long non-coding RNA HOXD-AS1 inhibits gastric cancer cell growth via inactivating the JAK2/STAT3 pathway. Tumour Biol 39: 1010428317705335,2017

27. Cesana M, Cacchiarelli D, Legnini I, Santini T, Sthandier O, Chinappi M, Tramontano A and Bozzoni I: A long noncoding RNA controls muscle differentiation by functioning as a competing endogenous RNA. Cell 147: 358-369, 2011.

28. Wang J, Liu X, Wu H, Ni P, Gu Z, Qiao Y, Chen N, Sun F and Fan Q: CREB up-regulates long non-coding RNA, HULC expression through interaction with microRNA-372 in liver cancer. Nucleic Acids Res 38: 5366-5383, 2010.

29. Zhou W, Ye XL, Xu J, Cao MG, Fang ZY, Li LY, Guan GH, Liu Q, Qian YH and Xie D: The lncRNA H19 mediates breast cancer cell plasticity during EMT and MET plasticity by differentially sponging miR-200b/c and let-7b. Sci Signal 10: 10, 2017.

30. Wang B, Shen ZL, Jiang KW, Zhao G, Wang CY, Yan YC, Yang Y, Zhang JZ, Shen C, Gao ZD, et al: MicroRNA-217 functions as a prognosis predictor and inhibits colorectal cancer cell proliferation and invasion via an AEG-1 dependent mechanism. BMC Cancer 15: 437, 2015. 
31. Flum M, Kleemann M, Schneider H, Weis B, Fischer S Handrick R and Otte K: miR-217-5p induces apoptosis by directly targeting PRKCI, BAG3, ITGAV and MAPK1 in colorectal cancer cells. J Cell Commun Signal: Sep 14, 2017 (Epub ahead of print). doi: 10.1007/s12079-017-0410-x.

32. Liu YP, Sun XH, Cao XL, Jiang WW, Wang XX, Zhang YF and Wang JL: MicroRNA-217 suppressed epithelial-to-mesenchymal transition in gastric cancer metastasis through targeting PTPN14. Eur Rev Med Pharmacol Sci 21: 1759-1767, 2017.

33. Lu L,LuoF,Liu Y,Liu X, Shi L, Lu X and Liu Q: Posttranscriptional silencing of the lncRNA MALAT1 by miR-217 inhibits the epithelial-mesenchymal transition via enhancer of zeste homolog 2 in the malignant transformation of $\mathrm{HBE}$ cells induced by cigarette smoke extract. Toxicol Appl Pharmacol 289: 276-285, 2015.

34. Deng S, Zhu S, Wang B, Li X, Liu Y, Qin Q, Gong Q, Niu Y, Xiang C, Chen J, et al: Chronic pancreatitis and pancreatic cancer demonstrate active epithelial-mesenchymal transition profile, regulated by miR-217-SIRT1 pathway. Cancer Lett 355 184-191, 2014.
35. Miao S, Mao X, Zhao S, Song K, Xiang C, Lv Y, Jiang H, Wang L, $\mathrm{Li}$ B, Yang X, et al: miR-217 inhibits laryngeal cancer metastasis by repressing AEG-1 and PD-L1 expression. Oncotarget 8: 62143-62153,2017.

36. Chen DL, Zhang DS, Lu YX, Chen LZ, Zeng ZL, He MM, Wang FH, Li YH, Zhang HZ, Pelicano H, et al: microRNA-217 inhibits tumor progression and metastasis by downregulating EZH2 and predicts favorable prognosis in gastric cancer. Oncotarget 6: 10868-10879, 2015.

This work is licensed under a Creative Commons Attribution-NonCommercial-NoDerivatives 4.0 International (CC BY-NC-ND 4.0) License. 